\title{
Evaluation of Radiculopathies by Segmental Stimulation and Somatosensory Evoked Potentials
}

\author{
Andrew Eisen, Maureen Hoirch and Alex Moll
}

\begin{abstract}
SUMMARY: Thirty-six patients with suspected or myelographically proven radiculopathies were investigated with motor and sensory conductions, F-waves, needle electromyography, and somatosensory evoked potentials (SEPs). SEPs were elicited by cutaneous nerve stimulation representative of input from individual cervical and lumbosacral dorsal roots. A myelographic defect was present in $83 \%$ of 30 patients who had myelograms. Overall $78 \%$ of patients had one or more abnormal electrophysiologic tests, the needle EMG giving the best diagnostic yield (75\%). F-waves and SEPs were abnormal in $43 \%$ and $57 \%$ of cases respectively. Motor deficit correlated best with abnormal EMGs, whilst abnormal SEPs occurred most frequently when sensory deficit predominated. Prolonged latency of the SEP occurred rarely, reduced amplitude or abnormal morphology being the most useful characteristics. SEPs evoked by cutaneous nerve stimulation are a useful addition to conventionally available electrophysiological methods of evaluating radiculopathies, especially in the absence of motor deficit.
\end{abstract}

RÉSUMÉ: Nous avons étudié, grâce aux conductions motrices et sensitives, aux ondes F, à l'électromyographie à l'aiguille et aux potentiels somatosensitifs évoqués (SEPs), 36 patients avec radiculopathies. Nous avons produit des SEPs par stimulation du nerf cutané approprié à chaque racine cervicale ou lombosacrée. Chez les 30 patients ayant subi une myélographie, $83 \%$ montraient un défaut radiologique. $78 \%$ des patients montraient des anomalies sur un ou plusieurs tests électrophysiologiques, l'EMG à l'aiguille étant le plus précis (75\%), suivi de l'onde F (43\%) et des SEPs (57\%). Les déficits moteurs correspondaient mieux aux anomalies de l'EMG, alors que les SEPs anormaux se trouvaient surtout lorsque le déficit sensitif était prédominant. Nous avons rarement trouvé une latence prolongée des SEP alors qu'une réduction d'amplitude ou une morphologie anormale s'avéraient utiles. En l'absence de déficit moteur, l'emploi des SEP par stimulation cutanées du nerf peut s'avérer une technique utile dans l'évaluation des radiculopathies.

Can. J. Neurol. Sci. 1983; 10:178-182

A nerve root lesion is defined as a motor or sensory deficit distributed in a myotomal or dermatomal pattern respectively. The electrophysiological evaluation of root lesions is important and the electromyographer must determine not only the segmental level(s) involved, but also the severity of physiological impairment. An isolated radiculopathy often is identifiable clinically and myelography allows visualization of the lesion in most instances. However, neither give information, especially early on in the disease, as to whether neurapraxia or axonal degeneration are primarily responsible for the deficit. Distinguishing between these is important prognostically. If more than one level is radiologically suspect it may be difficult solely on clinical grounds to determine if or which particular root is primarily causing symptoms.

A particular type of electrophysiological test seldom allows one to derive all the relevant information pertaining to a radiculopathy (Tonzola et al, 1981). Needle electromyography (EMG), especially of paraspinal muscles, helps identify the involved level(s) and is the only definitive means of documenting axonal degeneration and subsequent muscle re-innervation. However, evidence of denervation (fibrillation or positive sharp waves) requires from between ten days and four to five weeks to develop in paraspinal and distal limb musculature respectively (Knuttson, 1961; Gough and Koepke, 1966; Johnson and Melvin, 1971). F-wave measurements can usefully document slowed motor conduction proximally (roots). However, they are easily recordable from only a select group of muscles, having a limited myotomal representation (Kimura, 1974; Eisen et al, 1977a; Eisen et al, 1977b; Fisher et al, 1978). Furthermore, they give no information regarding sensory physiology (Mayer and Feldman, 1967; Miglietta, 1973). The H-reflex, although an excellent measure of conduction through the S1 sensory root, has a limited role because in the adult it cannot be recorded with ease other than from the gastrocnemius soleus muscle complex (Braddom and Johnson, 1974a; Braddom and Johnson, 1974b; Schuchman, 1978).

Sensory symptoms often predominate and may occur in isolation in radiculopathies. When this happens, EMG and F-wave studies are likely to be normal, but somatosensory evoked potentials (SEPs) might then complement these other electrophysiological methods of proven value in identifying root lesions. This study compares the relative value of EMG, $\mathrm{F}$-wave measurements, and SEPs in radiculopathies.

\section{MethodS}

Electrophysiological studies were performed on thirty-six patients ( 24 men and 12 women) between 19 and 76 years of age (mean 54.2 years) presenting with clinical features suggesting a radiculopathy. Thirty patients had myelograms. In the majority the results of myelography were not known prior to electrophysiological testing.

From the Department of Diagnostic Neurophysiology, Vancouver General Hospital, Vancouver, B.C.

Received February 23, 1983. Accepted for publication May 10, 1983.

Reprint requests to: Andrew Eisen, M.D., Diagnostic Neurophysiology - EMG, Vancouver General Hospital, 855 West 12th Avenue, Vancouver, B.C. V5Z 1M9 

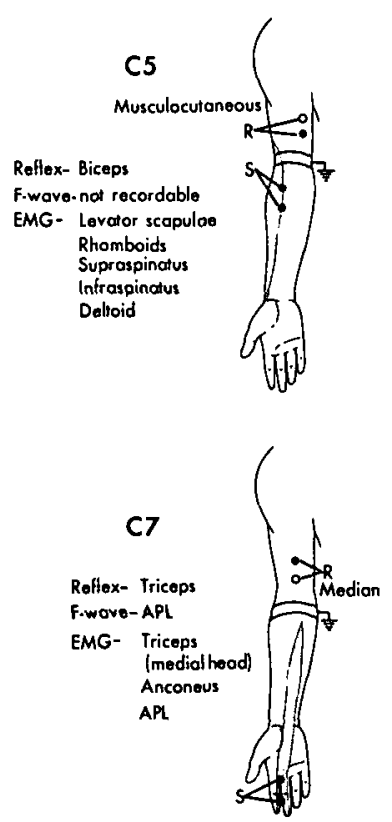
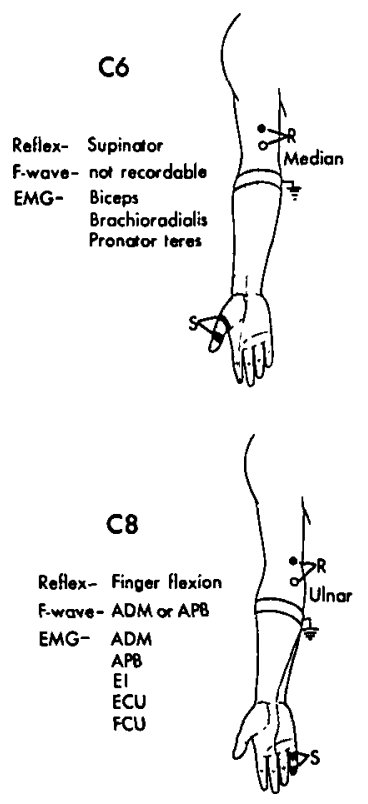

Figure 1 - The stimulating (S) and peripheral recording (R) sites used for cervical segmental stimulation ( $\mathrm{C} 5$ through $\mathrm{C8}$ ) are shown. For $\mathrm{C7}$ the adjoining surfaces of the second and third fingers are stimulated. The recording montage for the simultaneously recorded SEP is C3 or $\mathrm{C4}$ and Fz. The shaded areas reflect the appropriate dermatomes. Relevant muscles used for needle EMG and F-wave studies and the segmental deep tendon reflexes are also shown. $\mathrm{APL}=$ abductor pollicis longus; $\mathrm{ADM}=$ abductor digiti minimi; $\mathrm{APB}=$ abductor pollicis brevis; $\mathrm{El}=$ extensor indicis; $\mathrm{ECU}$ = extensor carpi ulnaris; $\mathrm{FCU}=$ flexor carpi ulnaris
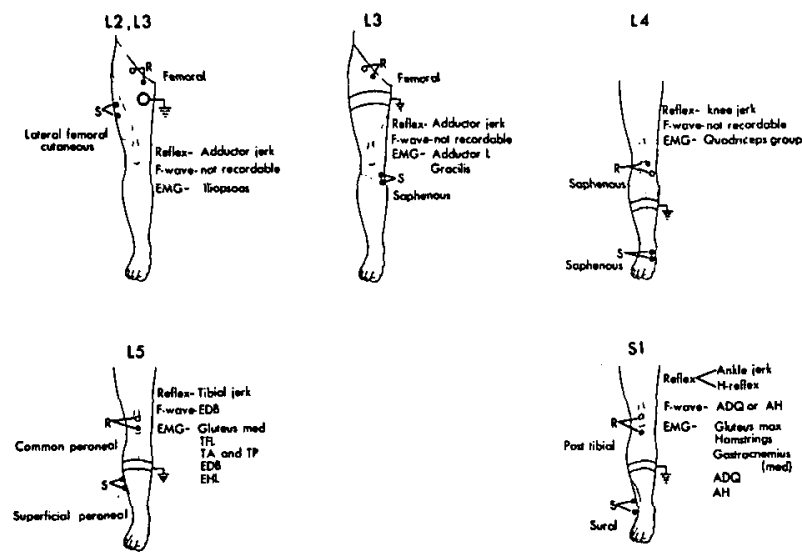

Figure 2 - As for figure one but depicting lumbar-sacral dermatomes. Stimulation of the saphenous at the knee and ankle reflect $\mathrm{L} 3$ and $\mathrm{LA}$ dermatomal activation respectively. The recording montage for the simultaneously recorded SEP is $\mathrm{Cz}$ and $\mathrm{Fz}$. EBD = extensor digitorum brevis; $\mathrm{TFL}=$ tensor fasciae latae; $\mathrm{TA}=$ tibialis anterior; $\mathrm{TP}=$ tibialis posterior; $\mathrm{EHL}=$ extensor hallucis longus; $\mathrm{ADQ}=$ abductor digiti quinti; $\mathbf{A H}=$ abductor hallucis.

Needle electromyography using a monopolar electrode was performed on appropriate paraspinal and limb muscles in each case. Studies were considered abnormal if fibrillations or positive sharp waves were present or if more than $15 \%$ of motor unit potentials recorded from a given muscle were polyphasic. Motor unit potentials were visualized with the aid of a delay line.
Reduced recruitment in association with increased firing rates of motor units (greater than 15 per second) was also considered abnormal. F-waves were recorded, measured, and categorized as normal or abnormal using previously described methods (Eisen et al, 1977a and b), (figures 1 and 2). SEPs were elicited using cutaneous nerve stimulation (figure 3). Stimulation sites chosen to most closely approximate activation of a single dermatome are shown in figures 1 and 2 . Stimulus intensity was 2.5 times sensory threshold, measuring between $4.5 \mathrm{~mA}$ and $13 \mathrm{~mA}$. Stimuli were delivered at 3 to 5 per second with a stimulus duration of $0.2 \mathrm{~m} \mathrm{sec}$. SEPs were recorded using scalp needle electrodes placed at $\mathrm{C} 3$ or $\mathrm{C} 4$ (contralateral to the side of stimulation), and $\mathrm{Fz}$ when stimulating an upper limb, and at $\mathrm{Cz}$ and $\mathrm{Fz}$ when stimulating a lower limb. Usually 512 epochs were averaged twice, but occasionally more extensive averaging was necessary. Latency of the SEP was measured to "N20" or "P40" stimulating an upper and lower limb cutaneous nerve respectively. SEPs were deemed abnormal when: 1) their latencies were prolonged by more than three standard deviations; above the normal mean value (table 1), 2) amplitude was reduced by $50 \%$ or more compared to an SEP evoked by stimulation of a contralateral homologous nerve, or an ipsilateral nerve representative of a segment above or below the one in question, (upper limb SEP amplitude was measured from P15 to N20 and lower limb SEP amplitude was measured from N30 to P40) or, 3) The SEP was a poor morphology compared to the contralateral homologous potential or an ipsilateral potential from a different segmental level. Only gross changes in morphology occurring in an otherwise technically sound record were considered abnormal. This abnormality was semiquantifiable using a computerized dispersion index measurement in which an index of $\mathbf{2 . 5}$ or greater is considered to be abnormal (Roberts et al, 1983).

Table 1: Stimulation sites and normal latencies for SEPs elicited by segmental sensory stimulation

\begin{tabular}{llcc}
\hline Cutaneous Nerve & \multicolumn{1}{c}{ Stimulation Site } & Segment & $\begin{array}{c}\text { Latency to N20 } \\
\text { or P40. mean } \pm\end{array}$ \\
\hline Musculocutaneous & forearm & C5 & $17.4 \pm 1.2$ \\
Median & thumb & C6 & $22.5 \pm 1.1$ \\
Median & $\begin{array}{l}\text { adjoining surfaces } \\
\text { fingers 2 and 3 }\end{array}$ & C7 & $21.2 \pm 1.2$ \\
Ulnar & finger 5 & C8 & $22.5 \pm 1.1$ \\
Lateral femoral & thigh & L2 & $31.8 \pm 1.8$ \\
cutaneous & & & \\
Saphenous & knee & L3 & $37.6 \pm 2.0$ \\
Saphenous & ankle & L4 & $43.4 \pm 2.2$ \\
Superficial personal & above ankle & L5 & $39.9 \pm 1.8$ \\
Sural & ankle & S1 & $42.1 \pm 1.4$ \\
\hline
\end{tabular}

A sensory nerve action potential (SNAP) was stimultaneously recorded at a proximal site along the appropriate cutaneous nerve (see figures 1 and 2). A near-nerve needle recording technique was used for this purpose (Buchthal et al, 1975), enabling dispersion as well as amplitude and latency of the SNAP to be accurately measured (Ludin and Tackmann, 1981). Measuring the SNAP was useful in monitoring the incoming volley and, therefore, the adequacy of the stimulus. When normal it was considered sufficient evidence to exclude peripheral sensory nerve disease. 


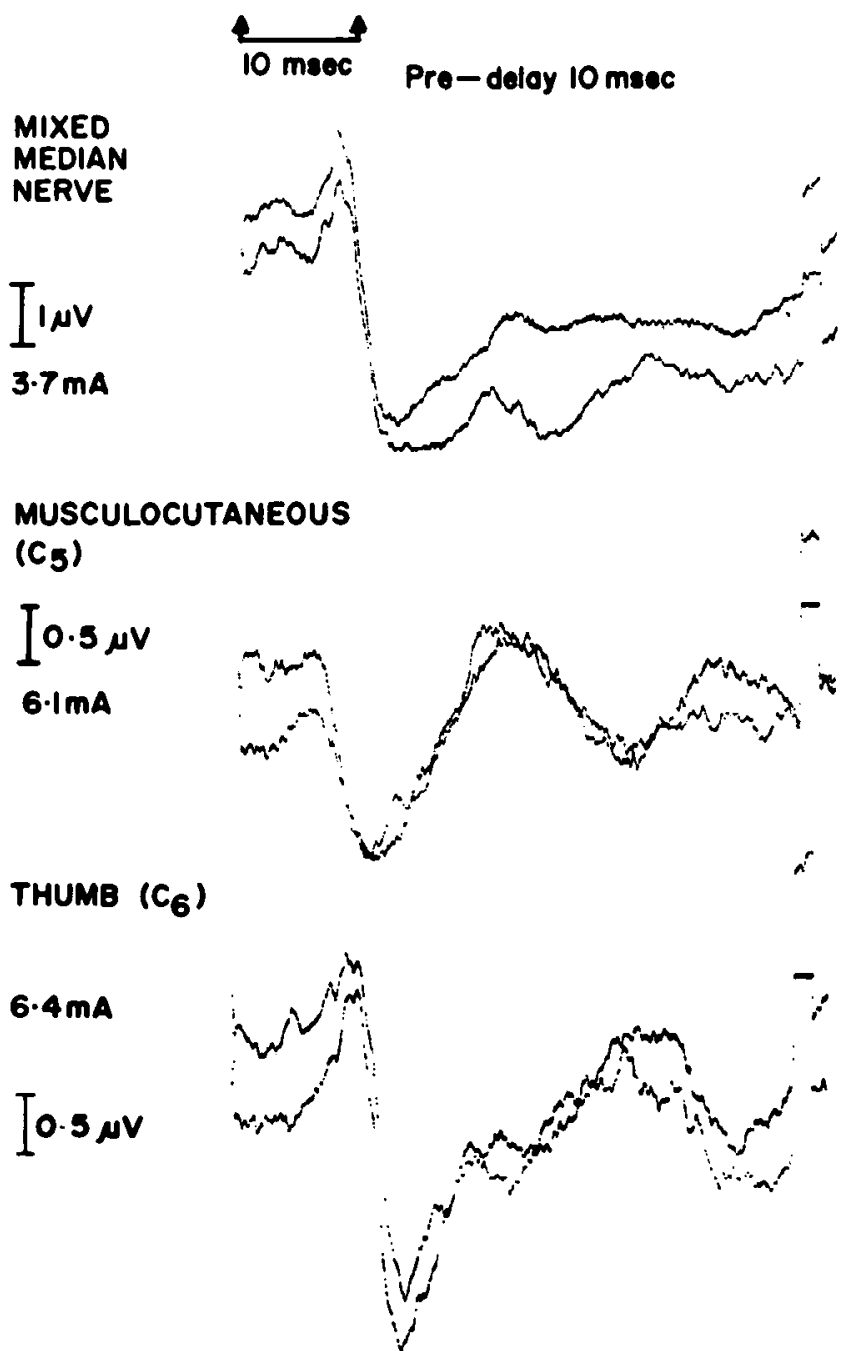

\section{Results}

Thirty patients had myelograms. A structural defect was visualized in 25 . Two had lumbar spinal arachnoiditis, 2 multisegmental metastases, and 21 disc disease ( 7 cervical and 10 lumbosacral). Nine patients had radicular pain without motor or sensory deficit, 4 showing myelographic evidence of root compression due to disc disease and five having normal myelograms. Of the 6 patients who did not have myelograms, 3 were considered to have diabetic lumbar radiculoplexopathy (Asbury, 1977), and the others suspected disc disease. All the patients with proven or suspected disc disease had had their symptoms for four weeks or more.

Table 2 summarizes and correlates electrophysiological results with the clinical deficit. In table 2 , sensory deficit refers to objective findings in a dermatomal distribution and appropriately
FINGERS 2 Q 3

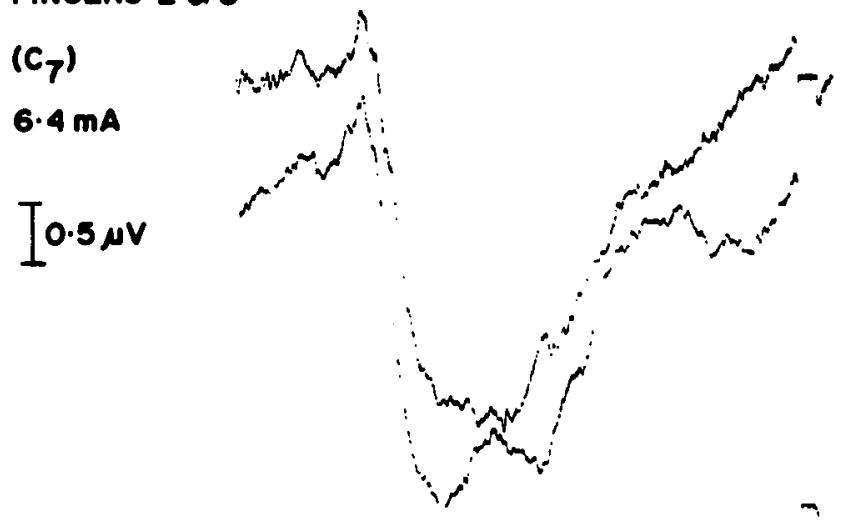

FINGER $5 \quad\left(C_{8}\right)$

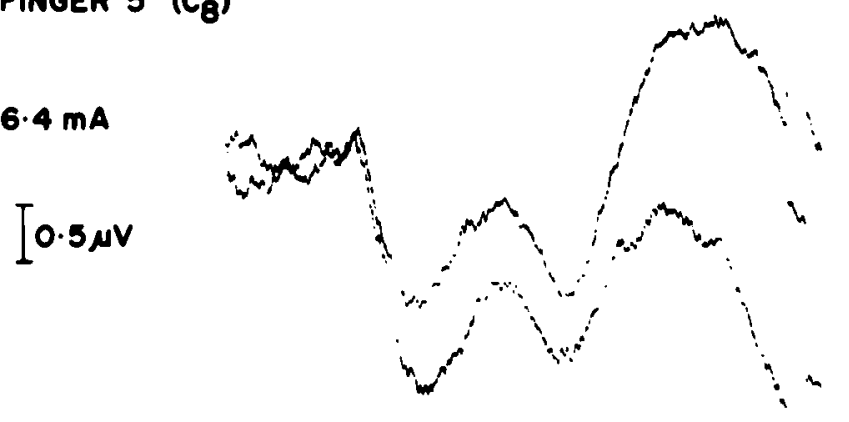

Figure 3 - Upper limb SEPs all recorded from the same normal subject. The stimulation sites and stimulus intensities are indicated. The amplitude of the SEP evoked by mixed median nerve stimulation is shown for comparison. It is about twice the size of the others, reflecting the much larger number of axons excited compared to cutaneous nerve stimulation. Only 256 sweeps were averaged in each total run.

depressed or absent deep tendon reflexes. Motor deficit means muscle wasting or weakness in a myotomal distribution. The patients with pain only had neither motor nor sensory deficit that could be objectively documented. The overall incidence of electrophysiological abnormalities $(78 \%)$ approximated that given by myelography (83\%). These abnormalities however, were not invariably found in the same patient. Needle EMG abnormalities occurred most frequently in association with motor deficit and SEP abnormalities were most common in association with a sensory deficit. Abnormal morphology (a dispersion index of greater than 2.5) was the most frequent SEP abnormality encountered in 12 out of 16 cases (see table 3). In 7 of these patients the SEP was also of reduced amplitude. Latency prolongation as an isolated abnormality occurred only once (figure 4). Needle electromyographic abnormalities were found

Table 2: Correlation between clinical deficit and electrophysiological Abnormalities in 36 patients with radiculopathies

\begin{tabular}{|c|c|c|c|c|c|}
\hline $\begin{array}{l}\text { Clinical } \\
\text { Deficit }\end{array}$ & $\begin{array}{c}\text { Number of } \\
\text { Patients }\end{array}$ & $\begin{array}{c}\text { Number (\%) } \\
\text { with any } \\
\text { Abnormal Test }\end{array}$ & $\begin{array}{c}\text { Number with } \\
\text { Abnormal } \\
\text { EMGs } \\
\end{array}$ & $\begin{array}{c}\text { Number with } \\
\text { Abnormal } \\
\text { F-Waves } \\
\end{array}$ & $\begin{array}{l}\text { Number with } \\
\text { Abnormal } \\
\text { SEPs }\end{array}$ \\
\hline Motor and sensory & 17 & $14(82 \%)$ & $12 / 14$ & $7 / 14$ & $9 / 14$ \\
\hline Motor only & 4 & $4(100 \%)$ & $4 / 4$ & $2 / 4$ & $1 / 4$ \\
\hline Sensory only & 6 & $4(67 \%)$ & $1 / 4$ & $1 / 4$ & $3 / 4$ \\
\hline Pain only & 9 & $6(67 \%)$ & $4 / 6$ & $2 / 6$ & 3.6 \\
\hline Total & 36 & $28(78 \%)$ & $21 / 28(75 \%)$ & $12 / 28(43 \%)$ & $16 / 28(57 \%)$ \\
\hline
\end{tabular}


in most of those cases who were going to show any type of electrophysiological abnormality. Sensory nerve action potentials were abnormal in latency, amplitude, or dispersion, only in the diabetic patients and 1 of the patients with radicular metastasis.

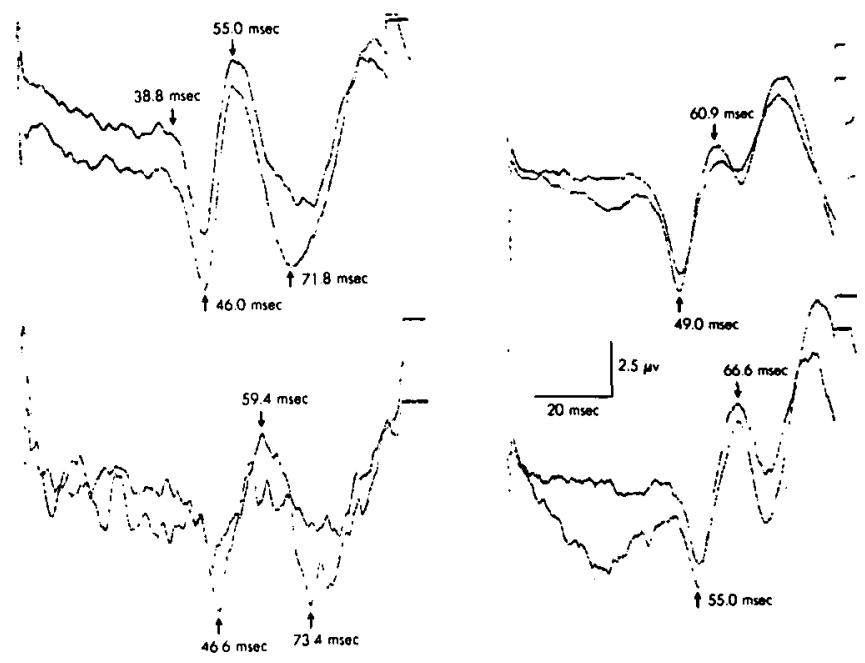

Figure 4 - The SEPs shown on the left were elicited by superficial peroneal nerve (L5) stimulation. The upper record is normal. The bottom record is of normal latency but poor morphology (dispersion index 4.2). The patient had a corresponding myelographically obvious disc herniation. The SEPs on the right recorded from a different patient were evoked by sural nerve stimulation. The latency of the lower record is very prolonged. The upper SEP is also slightly prolonged. The patient had a midline disc protrusion.

Table 3: Frequency of SEP abnormalities

\begin{tabular}{lc}
\hline \hline Type of SEP* Abnormality & Number of Cases \\
\hline Prolonged latency & 3 \\
Amplitude reduction & 10 \\
Abnormal morphology & 12 \\
\hline
\end{tabular}

* Nine patients had two or more different abnormalities.

\section{Discussion}

Prolongation of the latency of the cervical spinal or the lumbar spinal or the scalp recorded SEP is unusual in radiculopathy. In cervical radiculopathies there is usually associated spondylitic myelopathy before prolongation is seen (Chiappa and Ropper, 1982, El Negamy and Sedwick, 1979, Ganes, 1980, Siivola et al, 1981). The short segment of slowly conducting root is likely to be masked by the "diluting" efect of the long length of normally conducting peripheral nerve. A similar problem is encountered when using F-wave latencies to evaluate root lesions (Kimura, 1974, Eisen et al, 1977a, Eisen et al, 1977b, Fisher et al, 1978).

Amplitude reduction and poor morphology as defined by Roberts et al, (1983) were more useful abnormal SEP characteristics in our patients. Amplitude reduction may be the only abnormality reflecting conduction block in sensory fibres without concomitant slowing. SEP morphology may, also, be abnormal at a time when conduction is still relatively normal (see figure
4). Amplitude and morphologic change are, however, difficult to quantify, both having considerable normal variability. This is particularly true of the cervical and lumbosacral spinal evoked potentials which, for this reason, are unlikely to be useful in the electrophysiological evaluation or radiculopathies. This situation may change when it becomes possible to accurately measure SEP morphology and when standardized amplitude measurements are agreed upon.

Mixed nerve stimulation (the commonly preferred means of eliciting SEPs) activates several segmental levels. This is another limiting factor when evaluating root lesions, since they frequently involve only a single segmental level. Segmental cutaneous nerve stimulation helps overcome this problem. (Eisen and Elleker, 1980, Schramm et al, 1980, Jorg et al, 1982). It is not claimed that the sites chosen for cutaneous nerve stimulation (figures 1 and 2) always represent a single dermatome, but they are more selective than what is obtained with mixed nerve stimulation. Specificity may possibly be further improved by using a large surface cathode placed over a dermatome in conjunction with a small anode (relative monopolar stimulation). This method, however, has the disadvantage of producing a very asynchronous peripheral volley because of different conduction times in the fine cutaneous nerve twigs that are stimulated. The subsequent SEP is therefore likely to be small and of poor morphology. When using cutaneous nerve stimulation to evaluate nerve root dysfunction, it is important to monitor the incoming volley by recording a sensory nerve action potential along the course of the cutaneous nerve stimulated. A nearnerve needle recording technique is preferred, since at some sites it is difficult or impossible to record adequate sensory action potentials using surface electrodes. This is also the only means of allowing accurate measurement of dispersion of the sensory nerve action potential.

In evaluating sensory root lesions the SEP has a relationship to the sensory nerve action potential (SNAP) akin to that of the F-wave and $\mathrm{M}$-wave in motor root dysfunction. This is illustrated in figure 5. An abnormal SEP associated with a normal SNAp is excellent evidence for sensory root dysfunction, assuming that the central nervous system is normal. However, in some radiculopathies such as herpes zoster (Thomas and Howerd, 1974), and some types of diabetic radiculopathy (Asbury, 1977; Sun and Streib, 1981) in which loss or destruction of dorsal root ganglion cells occur, both the SEP and SNAP will be abnormal. These are true ganglionopathies.
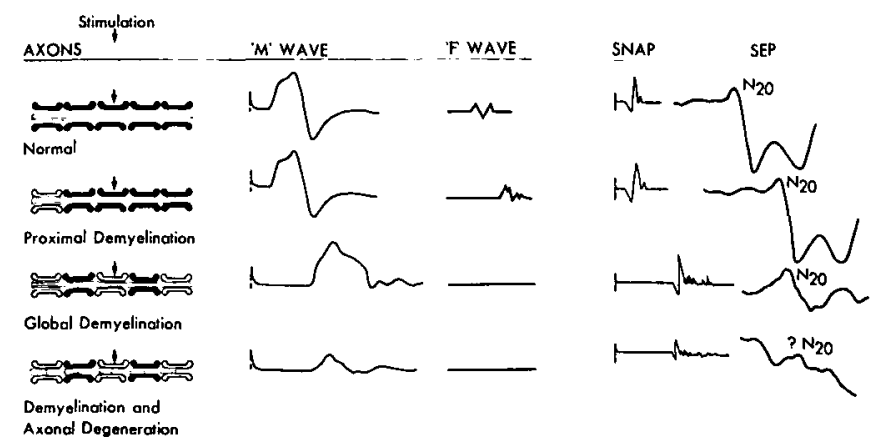

Figure 5-Schema comparing $M$ and $F$ waves to the SEP and SNAP. In a proximal root lesion the SEP and F-wave are prolonged in latency, reduced in amplitude or dispersed in shape. The $M$ wave and SNAP remain normal until demyelination or axonal degeneration spread distally. 
Cutaneous stimulation excites the slower conducting group II cutaneous afferents as opposed to the faster conducting group 1 muscle afferents activated by mixed nerve stimulation. Cutaneous nerve stimulation therefore elicits SEPs with slightly longer latencies than are obtained using mixed nerve stimulation, given stimulation and recording sites that are separated by comparable distances (Burke et al, 1981; Gandevia et al, 1982). Also, since the size of the SEP is directly proportional to the number of axons activated, SEPs evoked by cutaneous nerve stimulation will be proportionally smaller than those evoked through mixed nerve stimulation (see figure 3 ). To ensure that all the relevantly available cutaneous afferents are activated, a stimulus of 2 - 2.5 times threshold should be used. The best monitor of this, however, is the size of the sensory nerve action potential, which should be maximum. When this is achieved there is usually little difficulty in eliciting adequate SEPs in normal subjects.

Abnormalities of the SEP when elicited through mixed nerve stimulation are most likely to occur in association with loss of joint position sensation, vibration, or impaired two-point discrimination (Namerow, 1968). These clinical findings are, however, unusual in early root lesions, at least when due to compression when loss of light touch sensibility, pain and temperature discrimination, and dysesthesia are dominant. In this regard, it is more locigal to use cutaneous nerve stimulation to evoke SEPs when evaluating root lesions (and other diseases of the peripheral nervous system), than is mixed nerve stimulation, although centrally the two inputs are mediated via the same pathways. The ideal SEP would be one that reflects a given modality of sensation involving a specific dermatome. A clinically applicable technique for this has yet to be devised. Despite the several shortcomings of SEPs in the evaluation of radiculopathies, we believe they are useful, especially when segmental cutaneous stimulation is used. Their use should not take preference over other accepted electrophysiological methods such as needle EMG and F-wave studies, but when these are normal and the clinical complaints and deficit are predominantly or entirely sensory, then recording SEPs plays a useful role.

\section{REFERENCES}

Asbury, A.K. (1977). Proximal diabetic neuropathy. Ann Neurol, 2(3); 179-180.

Braddom, R.L., and Johnson, E.W. (1974a). Standadization of H reflex and diagnostic use in SI radiculopathy. Arch. Phys. Med. Rehabil., 55: $161-166$.

Braddom, R.L., and Johnson E.W. (1974b). H reflex: Review and classification with suggested clinical uses. Arch. Phys. Med. Rehabil., 55: 412-417.

Buchthal, F., Rosenfalck, A., and Behse, F. (1975). Sensory potentials of normal and diseased nerve. In: Peripheral Neuropathy, vol. 1, p. 422, edited by P.J. Dyck, P.K. Thomas, and E.H. Lambert. Saunders, Philadelphia.

Burke, D., Skuse, N.F., and Lethlean, A.K. (1981). Cutaneous and muscle afferent components of the cerebral potential evoked by electrical stimulation of human peripheral nerve. Electroencephalogr. Clin. Neurophysiol., 51: 579-588.

Chiappa, K.H., and Ropper, A.L. (1982). Evoked potentials in clinical medicine (part two). N. Engl. J. Med., 306: 1205-1211.
Eisen, A., Schomer, D., and Melmed, C. (1977a). The application of F-wave measurements in the differentiation of proximal and distal upper limb entrapments. Neurology, 27: 662-668.

Eisen, A., Schomer, D., and Melmed, C. (1977b). An electrophysiological method for examining lumbosacral root compression. Can. Neurol. Sci., 4: 117-123.

Eisen, A., and Elleker, G. (1980). Sensory nerve stimulation and evoked cerebral potentials. Neurology, 30: 1097-1105.

El Negamy, E., and Sedgwick, E.M. (1979). Delayed cervical somatosensory potentials in cervical spondylosis. J. Neurol. Neurosurg. Psychiatry, 42: 238-241.

Fisher, M.A., Shivde, A.J., Teixera, C., and Grainer, L.S. (1978). Clinical and electrophysiological appraisal of the significance of radicular injury in back pain. J. Neurol., Neurosurg. Psychiatry, 41: 303-306.

Gandevia, S., Burke, D., and McKeon, B. (1982). The relationship between the size of a muscle afferent volley and the cerebral potential it produces. J. Neurol., Neurosurg. Psychiatry, 45: 705-710.

Ganes, T. (1980). Somatosensory conduction times and peripheral cervical and cortical evoked potentials in patients with cervical spondylosis. Neurol. Neurosurg. Psychiatry, 43: 683-689.

Gough, J.C., and Koepke, G.H. (1966). Electromyographic determination of motor root levels in erector spinae muscles. Arch. Phys. Med. Rehabil., 47: 9-11.

Johnson, E.W., and Melvin, J.L. (1971). Value of electromyography in lumbar radiculopathy. Arch. Phys. Med. Rehabil., 52: 239-243.

Jorg, J., Dullberg, W., and Koeppen, S. (1982). Diagnostic value of segmental somatosensory evoked potentials in cases with chronic progressive para- or tetraspastic syndromes. In: Clinical Applications of Evoked Potentials in Neurology, pp. 347-358, edited by J. Courjon, F. Mauguiere, and M. Revol. New York, Raven Press.

Kimura, J. (1974). F-wave velocity in the central segment of the median and ulnar nerves. A study in normal subjects and in patients with Charcot-Marie-Tooth disease. Neurology, 24: 539-546.

Knuttson, B. (1961). Comparative value of electromyographic, myelographic, and clinical-neurological examinations in diagnosis of lumbar root compression syndrome. Acta Orthop. Scand., (suppl.) 49: 1-135.

Ludin, H.P., and Tackmann, W. (1981). Sensory Neurography. New York,. Thieme-Stratton Inc., pp.1-123.

Mayer, R.F., and Feldman, R.G. (1967). Observations on the nature of the F-wave in man. Neurology, 17: 147-156.

Miglietta, O.E. (1973). The F response after transverse myelotomy. In: New Developments in Electromyography and Clinical Neurophysiology, pp.323-327, edited by J.E. Desmedt. Karger: Basel.

Namerow, N.S. (1968). Somatosensory evoked responses in multiple sclerosis patients with varying sensory loss. Neurology, 18: 1197-1204.

Roberts, K.B., Lawrence, P.D., and Eisen, A. (1983). Dispersion of the somatosensory evoked potential (SEP) in multiple sclerosis. IEE Trans Biomed Engin (in press).

Schramm, J., Oettle, G.J., and Pichert, T. (1980). Clinical application of segmental somatosensory evoked potentials (SEP) - experience in patients with non-space occupying lesions. In: Evoked Potentials, pp.455-464, edited by C. Barber. Lancaster, MTP Press Lid.

Schuchmann, J.A. (1978), H-reflex latency in radiculopathy. Arch. Phys. Med. Rehabil., 59: 185-187.

Siivola, J., Salg, l., and Heiskari, M. (1981). Somatosensory evoked potentials in diagnostics of cervical spondylosis and herniated disc.

Sun, S.F., and Streib, E.W. (1981). Diabetic thoracoabdominal neuropahty Clinical and electrodiagnostic features. Ann. Neurol., 9: 75-79.

Thomas, J.E., and Howard, F.M. Jr. (1974). Segmental zoster paresis - a disease profile. Neurology, 22: 459-466.

Tonzola, R.F., Ackil, A.A., Shahani, B.T., and Young R.R. (1981). Usefulness of electrophysiological studies in the diagnosis of lumbosacral root disease. Ann. Neurol., 9: 305-308. 